\title{
A study on $\mathrm{CdCl}_{2}$ activation of $\mathrm{CBD}-\mathrm{CdS}$ films
}

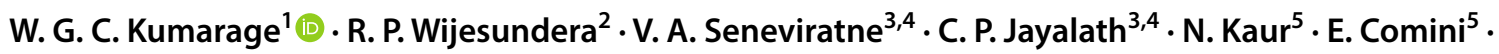 \\ N. Gunawardhana ${ }^{1} \cdot$ B. S. Dassanayake ${ }^{3,4}$
}

Received: 12 April 2020 / Accepted: 26 June 2020

(c) Springer Science+Business Media, LLC, part of Springer Nature 2020

\begin{abstract}
Cadmium sulfide (CdS) thin films were deposited using chemical bath deposition (CBD) technique on fluorine-doped tin oxide glass substrates. Cadmium sulfate, thiourea, and ammonium hydroxide were used as $\mathrm{Cd}$ source, $\mathrm{S}$ source, and the complexing agent, respectively in the reaction bath. The post-deposition $\mathrm{CdCl}_{2}$ activation of chemical bath deposited $\mathrm{CdS}$ (CBD-CdS) thin films was done by dip coating in a saturated $\mathrm{CdCl}_{2}$ bath. X-ray diffractograms show the growth of large $\mathrm{CdS}$ grains with better crystalline quality over the recrystallization process due to $\mathrm{CdCl}_{2}$ treatment. The development of large clusters was determined to be due to coalescence of smaller clusters. The photoelectrochemical (PEC) cell $\left(\mathrm{CdS} / \mathrm{Na}_{2} \mathrm{~S}_{2} \mathrm{O}_{3} /\right.$ Pt) parameters, such as $V_{O C}$ and $I_{S C}$ for $\mathrm{CdCl}_{2}$ activated CBD-CdS thin films were found to be higher compared to untreated CBD-CdS thin films. The improved effective surface area of the film and higher carrier concentration due to grain boundary passivation could be the reason for higher $V_{O C}$ and $I_{S C}$ values found in $\mathrm{CdCl}_{2}$-treated CdS films. Additionally, all the $\mathrm{CdCl}_{2}$-treated $\mathrm{CdS}$ films showed an increase in the optical transmittance spectra and bandgap compared to untreated $\mathrm{CdS}$ films. Relative energy band edge position of the grown CdS films was found to be adjustable with the $\mathrm{CdCl}_{2}$ treatment time . The best photoactivity was found for the $\mathrm{CdS}$ films which were dip-coated for $10 \mathrm{~min}$ in $\mathrm{CdCl}_{2}$ solution.
\end{abstract}

\section{Introduction}

Polycrystalline CdS thin films have shown potential photovoltaic applications due to its direct bandgap, high transmittance, low resistivity, and relative ease of film growth $[1,2]$. Among the dozens of growth techniques, chemical bath deposition (CBD) is considered as a favored technique of CdS thin film deposition due to its simplicity, low cost, adaptability, and reliability [3-8]. Additionally, the effect on growth kinetics, deposition bath temperature, chemical concentration, film thickness, and surface morphology to

B. S. Dassanayake

buddhikad@pdn.ac.lk

1 Research and International Affairs, Sri Lanka Technological Campus, Padukka, Sri Lanka

2 Department of Physics, University of Kelaniya, Kelaniya, Sri Lanka

3 Postgraduate Institute of Science, University of Peradeniya, Peradeniya, Sri Lanka

4 Department of Physics, University of Peradeniya, Peradeniya, Sri Lanka

5 Department of Information Engineering, Università Degli Studi Di Brescia, Brescia, Italy achieve improved photo active CBD-CdS thin film has been comprehensively reported in previous studies [9-12]. Subject to the growth condition and technique, CdS film can be found in either metastable cubic or highly stable hexagonal phase [13]. Since better crystallinity of the window layer in photovoltaic devices is a must to achieve superior light to current efficiency, it is crucial to improve the crystallinity of CdS to produce superior devices [2,14].

$\mathrm{CdCl}_{2}$ heat treatment on CdTe is well known since the 1970s to improve the conversion efficiency of $\mathrm{CdTe} / \mathrm{CdS}$ solar cells [15-17]. Also, $\mathrm{CdCl}_{2}$ treatment offers several significant benefits such as grain boundary passivation, increase of grain size, reduction of lattice mismatch between the $\mathrm{CdS}$ and CdTe layers, resulting in improved efficiency of conversion of light to current in the CdS/CdTe solar cells [18]. However, few articles have been reported the $\mathrm{CdCl}_{2}$ heat treatment on CdS [19]. Among different types of post deposition heat treatment methods, $\mathrm{CdCl}_{2}$ treatment on $\mathrm{CdS}$ thin films can be considered as a crucial method to grow highquality CdS thin films [19].

Conventionally, there are three major $\mathrm{CdCl}_{2}$ treatment methods; wet treatment [20], evaporated treatment [21], and vapor treatment [22]. In this manuscript, a comprehensive investigation is reported on conventional wet treatment on 
chemical bath deposited CdS (CBD-CdS) by the means of photoelectochemical (PEC) cell measurements, $C-V$ measurements, field emission scanning electron microscopy (FESEM), optical measurements, and grazing incidence X-ray diffraction (GIXRD).

\section{Experiment}

$0.001 \mathrm{~mol} \mathrm{dm}^{-3} 3 \mathrm{CdSO}_{4} \cdot 8 \mathrm{H}_{2} \mathrm{O}$ (cadmium sulfate, Sigma Aldrich, 99\%, USA), $0.002 \mathrm{~mol} \mathrm{dm}{ }^{-3} \mathrm{CS}\left(\mathrm{NH}_{2}\right)_{2}$ (thiourea, Sigma Aldrich, 99\%, USA) and $1.1 \mathrm{ml} \mathrm{NH}_{3}$ (ammonia, Sigma Aldrich, 35\% w/w, USA) were used as the starting chemical for the growth of CBD-CdS thin films. Bath temperature was kept at $80^{\circ} \mathrm{C}$ for $1 \mathrm{~h}$ over the course of CBD process using FTO $(\sim 10 \Omega / \square$, TEC 10 , Sigma Aldrich, USA) glass substrates. Cleaning of the substrate and grown films was carried out according to the procedure explained in Kumarage et al.[23]. All the grown CdS thin films were about $80 \mathrm{~nm}$ in thickness. Later, the grown films underwent dip coating with saturated $\mathrm{CdCl}_{2}$-methanol $\left(\mathrm{CdCl}_{2}\right.$, Fluka, 99\%, USA; methanol, Sigma Aldrich, 99.8\%, USA) solution. The $\mathrm{CdCl}_{2}$ treatment duration was varied from 2 to $20 \mathrm{~min}$. Later, all the grown films were annealed at $200{ }^{\circ} \mathrm{C}$ for $1 \mathrm{~h}$. The coding of the grown films corresponding to the treatment duration time is denoted in Table 1 .

\section{Characterizations}

The morphological study of the grown CdS films was done using an FE-SEM model LEO 1525. All the GIXRD analysis of grown films were examined in a PANalytical diffractometer (Empyrean) with a monochromatic beam of $\operatorname{CuK} \alpha(\lambda=1.54184 \AA)$ with $2^{\circ}$ incident angle, working under $40 \mathrm{~mA}$ tube current at $40 \mathrm{kV}$. UV-1800 Shimadzu spectrophotometer was employed to examine the optical properties of the grown CdS films in the optical window of $300-800 \mathrm{~nm}$. Profilometer (XP-1) was used to measure the thickness of grown CdS films. All the photoelectrochemical (PEC) cell analyses were carried out for the structure of Pt/

Table 1 CdS film codes and the dipping durations for $\mathrm{CdCl}_{2}$ treatment

\begin{tabular}{ll}
\hline $\begin{array}{l}\text { Dipping dura- } \\
\text { tion (minutes) }\end{array}$ & CdS film code \\
\hline 0 & S-0 \\
2 & S-2 \\
6 & S-6 \\
10 & S-10 \\
14 & S-14 \\
18 & S-18 \\
20 & S-20 \\
\hline
\end{tabular}

$\mathrm{Na}_{2} \mathrm{~S}_{2} \mathrm{O}_{3} / \mathrm{CdS} / \mathrm{FTO}$ using PEC Cell L01. A $150 \mathrm{~W}$ short-arc xenon lamp was used to illuminate the CdS/electrolyte junction. The same PEC cell configuration was used for the $C-V$ measurements. A sinusoidal signal of $1000 \mathrm{~Hz}$ with a voltage of $20 \mathrm{mV}$ corresponding to the $\mathrm{Ag} / \mathrm{AgCl}$ electrode was used to bias the CdS/electrolyte junction. The electrolyte used for all the electrical characterizations was $0.1 \mathrm{~mol} \mathrm{dm}^{-3}$ $\mathrm{Na}_{2} \mathrm{~S}_{2} \mathrm{O}_{3}$ (Baxter Smith Labs, 97\%, USA) and the semiconductor to electrolyte contact area was $0.25 \mathrm{~cm}^{2}$.

\section{Results and discussion}

\subsection{Optical measurements}

The optical bandgap $\left(E_{g}\right)$ values of the grown films were calculated by extrapolating the straight portions of the curves of $(\alpha h v)^{2}$ vs. $h v$ onto the "h $v$ " axes using the Stern relation [24-27]:

$\alpha=\mathrm{A} \frac{\left(\mathrm{h} v-\mathrm{E}_{\mathrm{g}}\right)^{n / 2}}{\mathrm{~h} v}$

where $\alpha$ is the optical absorption coefficient, $h$ is the Plank's constant, $A$ is a constant and for direct bandgap materials such as CdS, $n$ is equal to 1 . Variation of $E_{g}$ of the grown CdS thin films corresponding to the $\mathrm{CdCl}_{2}$ dipping times is shown in Fig. 1. The film S-10 demonstrations the highest value of $2.41 \mathrm{eV}$ in $E_{g}$, whereas the lowest $2.33 \mathrm{eV}$ was observed in S- 0 . The variation in $E_{g}$ of CBD-CdS thin films could be associated with changes in the lattice strain due to the recrystallization as a result of $\mathrm{CdCl}_{2}$ heat treatment [28]. Additionally, the results propose that the $E_{g}$ values of

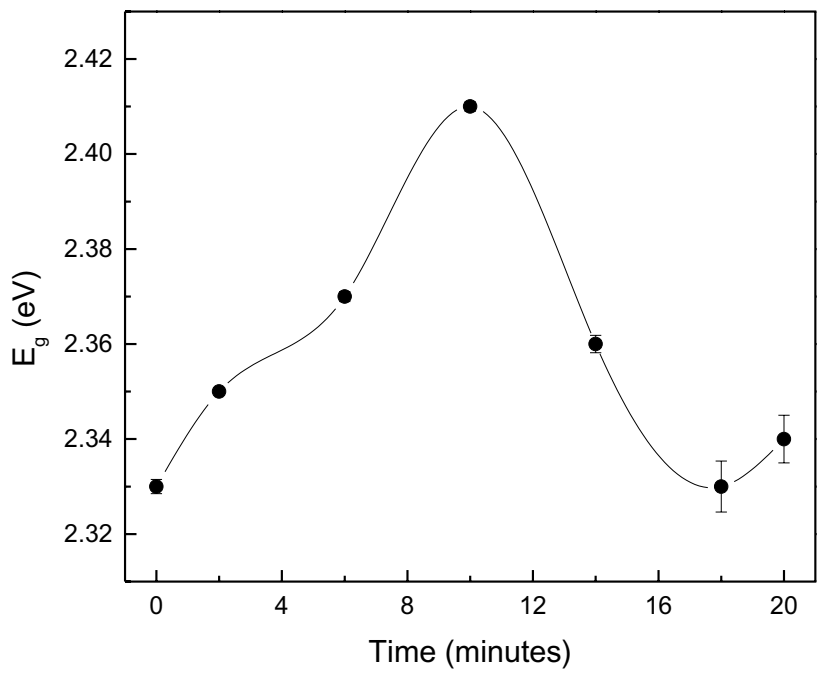

Fig. $1 E_{g}$ variation of the $\mathrm{CdCl}_{2}$-treated $\mathrm{CdS}$ thin films 
the CBD-CdS can be tuned between 2.33 and $2.41 \mathrm{eV}$ by varying the $\mathrm{CdCl}_{2}$ treatment time.

The optical transmittance results in the optical window of 300-800 nm of the grown CdS on FTO corresponding to $\mathrm{CdCl}_{2}$ treatment times are presented in Fig. 2. The optical transmittance edge of all the $\mathrm{CdCl}_{2}$ activated films shows a blue-shift compared to the untreated, justifying the alteration of $E_{g}$ value with the $\mathrm{CdCl}_{2}$ treatment time observed in Fig. 1. Further, it can also be seen that all the $\mathrm{CdCl}_{2}$ activated films have comparatively high transmittance below the optical bandgap compared to the untreated films, though the films are in the same thickness range. The highest optical transmittance was yielded for the films grown with a $\mathrm{CdCl}_{2}$ treatment time of $10 \mathrm{~min}$. The improvements in the optical transmittance also suggests low concentration of defects and better CdS crystal quality. The improvement in the crystal quality may diminish the absorption of light in the longer wavelength region, subsequently enhance the electrical properties [27, 29].

\subsection{Structural characterization}

Figure 3 shows GIXRD diffractograms of (a) $\mathrm{CdCl}_{2}$-treated film which showed the highest optical bandgap and the highest transmittance, (b) untreated CBD-CdS, and (c) bare FTO glass. Results suggest that the deposited CBD-CdS films are in the hexagonal phase. Five diffraction peaks were found to originate from diffraction angles $25.07^{\circ}, 26.46^{\circ}, 28.32^{\circ}$, $44.10^{\circ}$ and $48.34^{\circ}$. The peaks were identified to be hexagonal reflections of (100), (002), (101), (110) and (103) planes of CdS (JCPDS 98-009-5006). The rest of the peaks belong to the FTO substrate. Figure $3 \mathrm{a}$ and Table 2 show the existence of broad asymmetric peaks $\left(25.19^{\circ}, 26.52^{\circ}\right.$ and $\left.44.18^{\circ}\right)$ in $\mathrm{CdCl}_{2}$-treated films with a tail extending towards higher

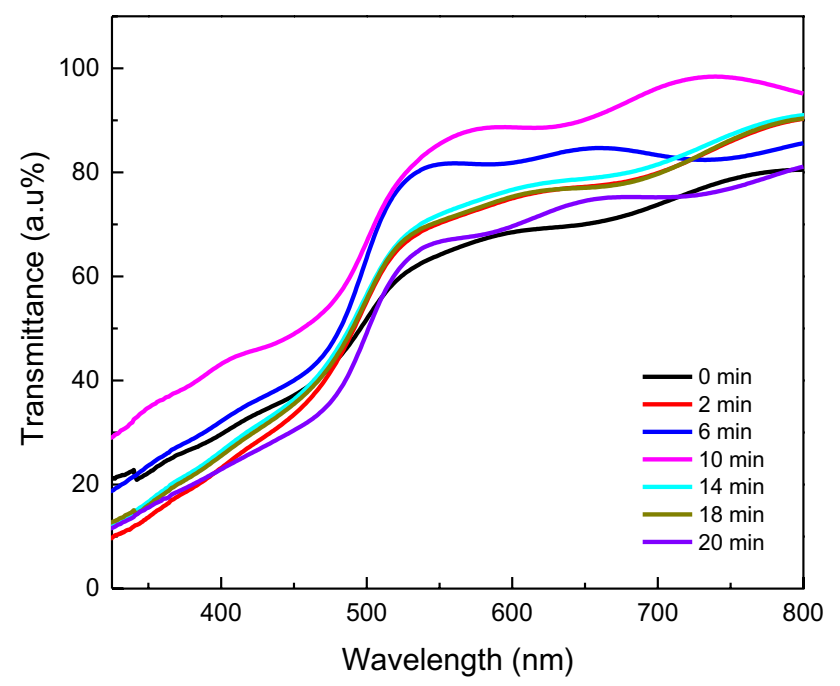

Fig. 2 Transmittance variation of the $\mathrm{CdCl}_{2}$-treated $\mathrm{CdS}$ thin films

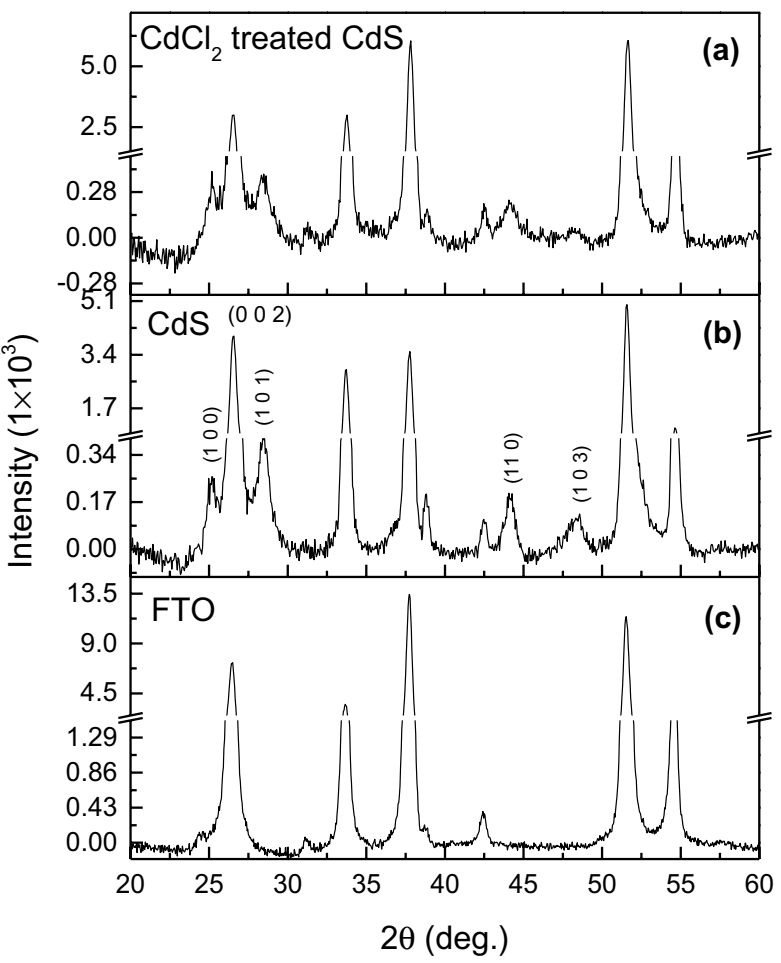

Fig. 3 GIXRD diffractograms of a $\mathrm{CdCl}_{2}$-treated $\mathrm{CdS}$, $\mathbf{b} \mathrm{CdS}$ on FTO c Bare FTO glass

angles. These asymmetric peaks can be originating from the primary recrystallization of $\mathrm{CdS}$ due to broken $\mathrm{Cd}-\mathrm{S}$ bonds since $\mathrm{CdCl}_{2}$ behaves as a fluxing agent [29]. Hence it is worth to discuss the mechanism that could potentially affect the recrystallization.

Conventionally, there is an excess number of sulfur vacancies in $\mathrm{CdS}$ films associated with that of the interstitial cadmium $\left(\mathrm{Cd}_{\mathrm{i}}\right)$. The chemical route of forming $\mathrm{Cd}_{\mathrm{i}}$ and releasing $\mathrm{S}$ from the $\mathrm{CdS}$ along with the $\mathrm{CdCl}_{2}$ treatment can be explained as follows [19]:

$\mathrm{CdS}+\mathrm{CdCl}_{2} \rightarrow 2 \mathrm{Cl}_{\mathrm{s}}+2 \mathrm{Cd}_{\mathrm{i}}+1 / 2 \mathrm{~S}_{2(\mathrm{~g})}$

where $X_{\mathrm{i}}$ and $X_{\mathrm{s}}$ denote the interstitial position and substitutional position of an element respectively. Hence, a significant quantity of $\mathrm{Cl}$ atoms diffuses into the $\mathrm{CdS}$ films along

Table 2 Two theta angle and the corresponding reflection plane

\begin{tabular}{|c|c|c|c|c|}
\hline \multirow[t]{2}{*}{ Plane } & \multicolumn{2}{|c|}{ Untreated CdS } & \multicolumn{2}{|c|}{$\begin{array}{l}\mathrm{CdCl}_{2} \text {-treated CdS } \\
(\mathrm{S}-10)\end{array}$} \\
\hline & $2 \theta\left(^{\circ}\right)$ & $d(\AA)$ & $2 \theta\left(^{\circ}\right)$ & $d(\AA)$ \\
\hline 100 & 25.1196 & 3.54522 & 25.1960 & 3.53464 \\
\hline 002 & 26.4882 & 3.36506 & 26.5289 & 3.35999 \\
\hline 110 & 44.1554 & 2.05111 & 44.1835 & 2.04987 \\
\hline
\end{tabular}


with the annealing process and create $\mathrm{Cl}_{\mathrm{s}}$ state. Furthermore, with the introduction of $\mathrm{Cl}_{\mathrm{s}}$ state in the $\mathrm{CdS}, \mathrm{V}_{\mathrm{Cd}}{ }^{2+}$ and $\mathrm{Cl}_{\mathrm{s}}$ are formed to create deep and shallow levels $\left(\mathrm{V}_{\mathrm{x}}\right.$ denote a vacancy) [30]. Thereby it can be concluded here, most of the sulfur vacancies are chemically engaged by the $\mathrm{Cl}^{-}$ions to form $\mathrm{Cl}_{\mathrm{s}}$. As the $\mathrm{Cl}_{\mathrm{s}}$ occupied in $\mathrm{V}_{\mathrm{s}}$, it prevents oxygen incorporation on $\mathrm{CdS}$ during the $\mathrm{CdCl}_{2}$ treatment. Thereby in the annealing process, nanoscale grains will coalesce to form a dense film [19]. Also, Cd vacancies are created in the $\mathrm{CdS}$ matrix to maintain the overall charge neutrality along with the incorporation of $\mathrm{Cl}^{-}$ions. This formation of $\mathrm{Cd}$ vacancies enables enough space for the rearrangement of atoms during the recrystallization process, promoting coalescence of neighboring clusters.

In order to examine the preferential crystallite alignment of the grown CdS films, the texture coefficient $\left(T C_{h k l}\right)$ of $\mathrm{CdCl}_{2}$-treated $(10 \mathrm{~min})$ films and untreated was calculated. For the $T C_{h k l}$ calculation following equation was used [31-35]:

$T C_{h k l}=\frac{I_{(h k)} / I_{(h k l)}}{1 / n\left[\sum_{i=1}^{n} I_{(h k)} / I_{0(h k l)}\right]}$

where $n$ is the number of X-ray diffraction peaks, $I_{(h k l)}$ is the measured intensity and $I_{0(h k l)}$ is the standard intensity of the plane $(h k l)$. The standard intensity of the plane $(h k l)$ was taken from the JCPDS 98-009-5006. The $T C_{h k l}$ for films S-0 and S-10 are displayed in Fig. 4. The figure illustrates that the relative intensity of the peaks (100) and (101) increase with the $\mathrm{CdCl}_{2}$ treatment, while the intensity of (002) decreases. Yet, the results indicate that the reflection plane (002) seems to be the favored orientation for both investigated films S-0 and S-10.

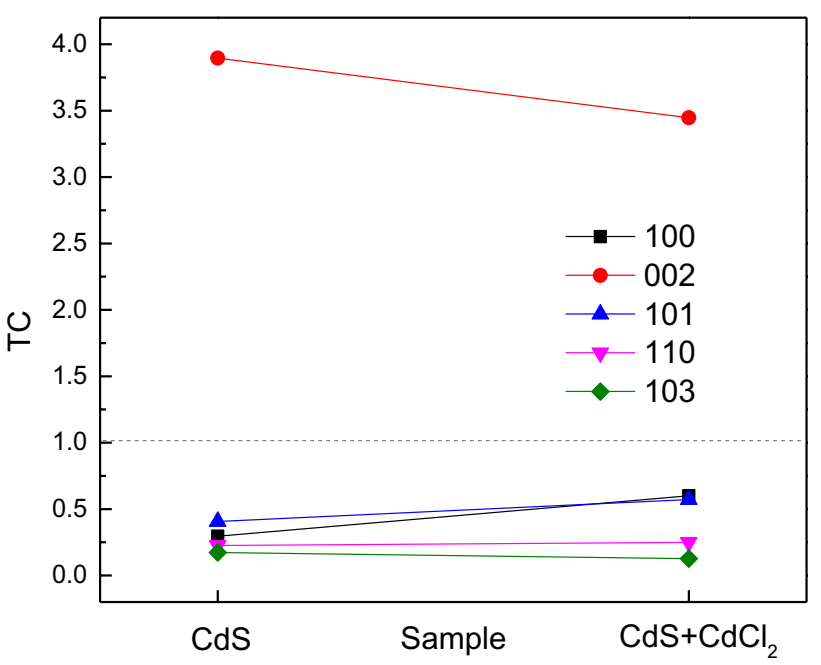

Fig. 4 The texture coefficient of a CdS, $\mathbf{b} \mathrm{CdCl}_{2}$-treated CdS films

\subsection{Morphological characterization}

The SEM images of four different films are presented in Fig. 5a-d. The figure suggests that the cluster sizes have increased with the $\mathrm{CdCl}_{2}$ treatment. Additionally, Fig. $5 \mathrm{~b}$ shows the established large grains over the course of $\mathrm{CdCl}_{2}$ annealing are made due to the coalescence of small clusters. These coalesced grains could be due to a result of the division of bigger grains into smaller grains and reorienting themselves as discussed earlier, affecting the overall microstructure [36, 37]. As the $\mathrm{CdCl}_{2}$ treatment time increases up to $10 \mathrm{~min}$, spherical clusters about $50-100 \mathrm{~nm}$ appear on the surface which have not coalesced together. Pinholes were not found in the film. The increment of the grain size of the $\mathrm{CdCl}_{2}$-treated films can potentially be due to the diffusion of $\mathrm{CdCl}_{2}$ into the $\mathrm{CdS}$ film, reorienting the microstructure [16].

\subsection{PEC cell characterization}

Figure 6 illustrates the variation of $V_{O C}$ and $I_{S C}$ with $\mathrm{CdCl}_{2}$ treatment time. The figure manifests both the superior $I_{S C}$ and $V_{O C}$ values shown by all the films that underwent $\mathrm{CdCl}_{2}$ treatment (Table 3). Consequently, the highest $I_{S C}$ and $V_{O C}$ values were shown by the film $\mathrm{S}-10$. The observed superior $I_{S C}$ values in the $\mathrm{CdCl}_{2}$-coated films potentially resulted from the improved gain size as observed in Fig. 5. Additionally, the highest $I_{S C} \times V_{O C}$ was seen for S-10, suggesting better photoactivity of the film.

Improved electrical properties of $\mathrm{CdCl}_{2}$-treated films can be understood by looking into the structural changes which undergo as a result of the $\mathrm{CdCl}_{2}$ treatment. The presence of $\mathrm{Cl}^{-}$, resulting from $\mathrm{CdCl}_{2}$ treatment has been identified to act as a fluxing agent that supports the grain growth process [38]. Also, the existence of large grains reduces the number of grain boundaries as well as the scattering of charge carriers at the grain boundaries [38]. Therefore, a detailed explanation of the improvement of electrical properties is worth discussing here.

The mobility of the carriers in the films is affected by several factors including carrier concentration, annealing temperature, and defect complex formation. As the annealing temperature was kept at constant $\left(200{ }^{\circ} \mathrm{C}\right)$ throughout the work, the effect of annealing temperature can be ruled out from the discussion. The increment of the $I_{S C}$ value up to $10 \mathrm{~min}$ of $\mathrm{CdCl}_{2}$ treatment time can be attributed from the increment of carrier concentration with the $\mathrm{CdCl}_{2}$ treatment time as shown in Table 3. The decrement in the $I_{S C}$ value beyond the treatment time of $10 \mathrm{~min}$ can be due to the increment of charged defect complexes with a growing diffusion concentration of $\mathrm{Cl}^{-}$. These defect centers surge the scattering rate for the carriers, reducing the mobility of carriers in the deposited films. Additionally, with the increment of $\mathrm{Cl}$ diffusion into $\mathrm{CdS}$, vacant centers are filled with charge 

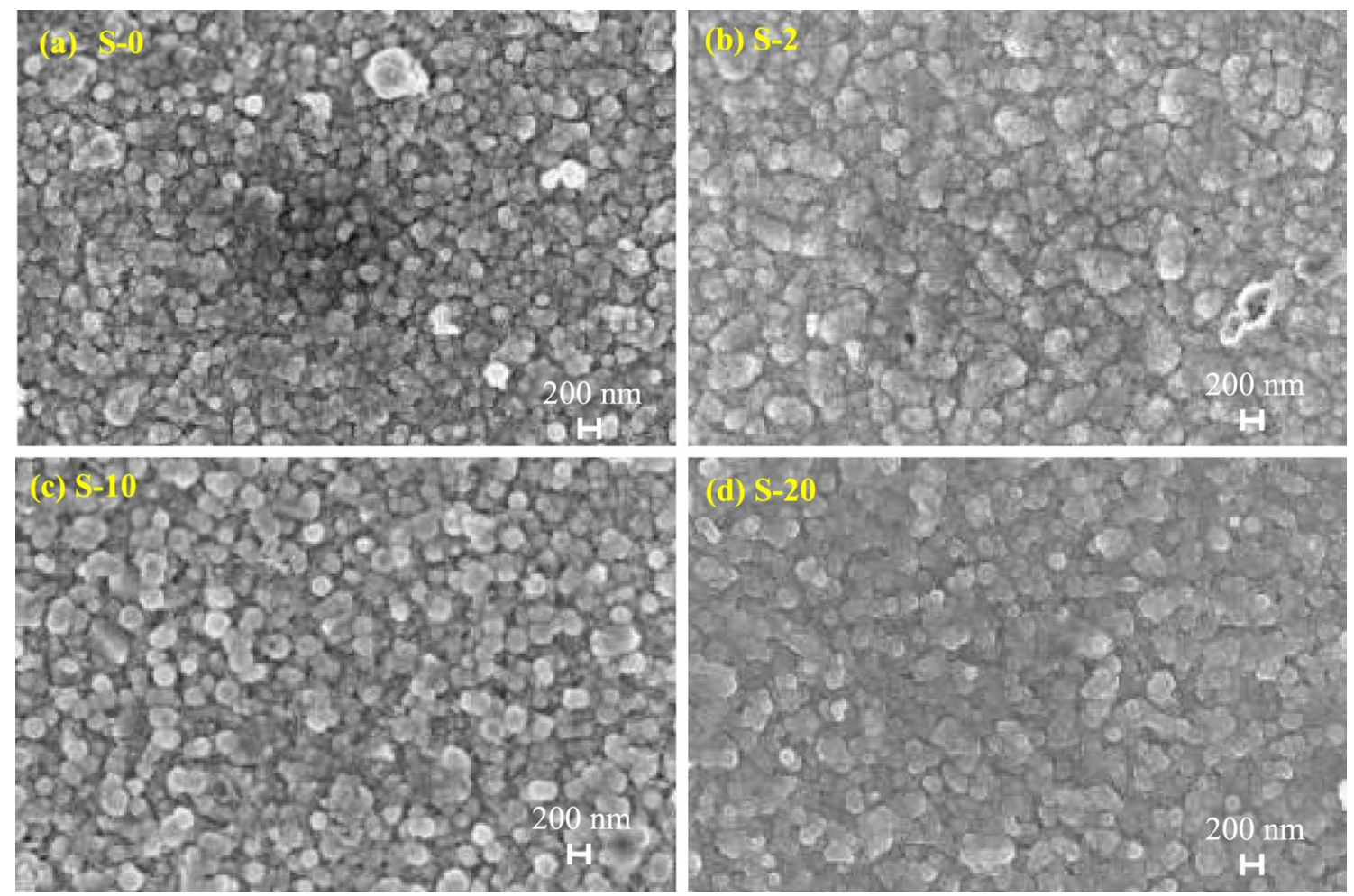

Fig. 5 Scanning electron microscope images of the grown $\mathrm{CdS}$ films; a $\mathrm{CdCl}_{2}$ treatment time 0 min, $\mathbf{b} \mathrm{CdCl}_{2}$ treatment time 2 min, $\mathbf{c} \mathrm{CdCl}_{2}$ treatment time $10 \mathrm{~min}$ and $\mathbf{d ~} \mathrm{CdCl}_{2}$ treatment time $20 \mathrm{~min}$

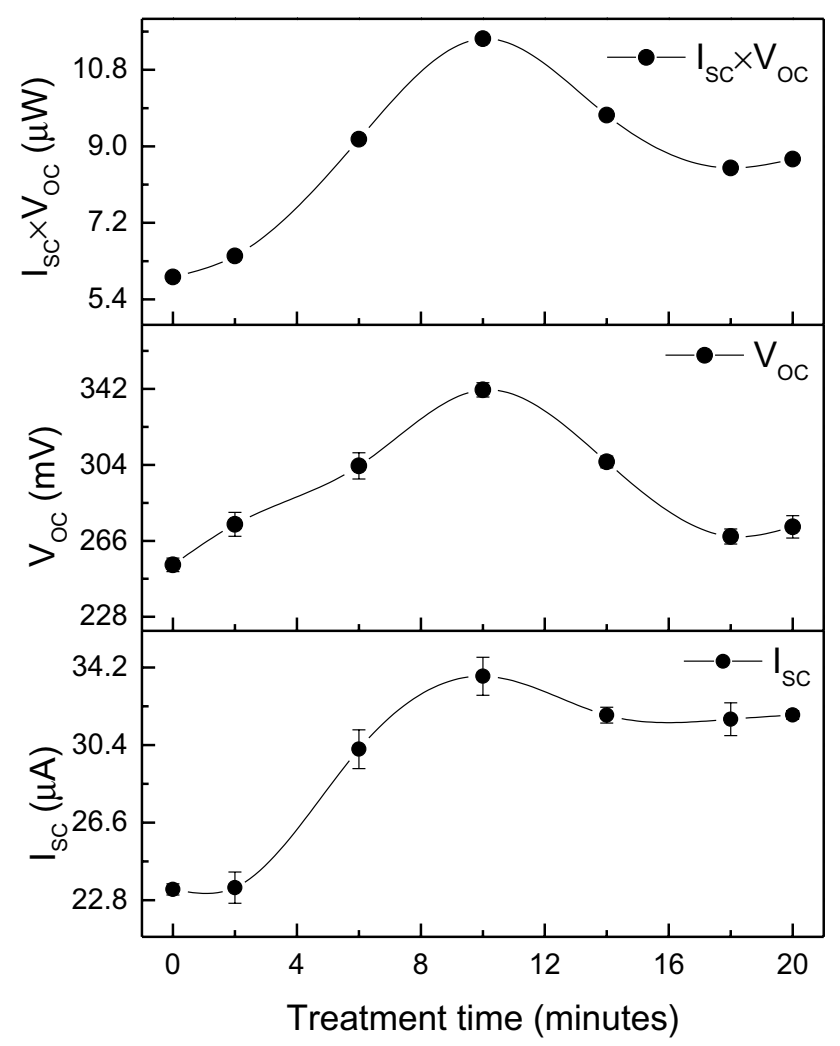

Fig. 6 Open circuit voltage $\left(V_{O C}\right)$, short circuit current $\left(I_{S C}\right)$ and $I_{S C} \times V_{O C}$ for the $\mathrm{CdCl}_{2}$-treated CdS thin films carriers. Subsequently, these filled centers create potential barriers near the grain boundary which limits the mobility of carrier charges.

\subsection{C-V measurement}

Carrier concentration $\left(N_{D}\right)$ and $V_{f b}$ were found from the slope and the $\mathrm{X}$-axis intercept of the linear fit of the MottSchottky equation [39]:

$\frac{1}{C^{2}}=\frac{2}{A \varepsilon \varepsilon_{0} N_{D}}\left(V-V_{f b}-\frac{k T}{e}\right)$

where $e$ is the electron charge, $A$ is the area, $\varepsilon_{0}$ is the permittivity in a vacuum and $\varepsilon(=8.5)$ is the dielectric constant [40]. The shape of the gradient of Mott-Schottky plot (1/ $C^{2}$ vs. V) confirms all the grown films are n-type in nature. Fig. 7 and Table 3 show the variation of $V_{f b}$ of grown films corresponding to the $\mathrm{CdCl}_{2}$ treatment time. These results facilitate visualization of the altering nature of the relative energy band edge position in the bandgap of the grown films corresponding to $\mathrm{CdCl}_{2}$ treatment time.

All the $\mathrm{CdCl}_{2}$-treated films showed significantly high $V_{f b}$ (with S-10 presence the highest), suggesting the existence of different energy band edge positions in the $\mathrm{CdCl}_{2}$-treated films compared to untreated. The relative band edge position 
Table 3 Variation of electrical and optical bandgap of the $\mathrm{CdCl}_{2}$-treated films

\begin{tabular}{lllllll}
\hline $\begin{array}{l}\text { Dipping time } \\
\text { (minutes) }\end{array}$ & $I_{S C}(\mu \mathrm{A})$ & $V_{O C}(\mathrm{mV})$ & $I_{S C} \times V_{O C}(\mu \mathrm{W})$ & $E_{g}(\mathrm{eV})$ & $V_{f b}(\mathrm{mV})$ & $N_{D}\left(10^{16} \mathrm{~cm}^{-3}\right)$ \\
\hline 0 & 23.32 & 254.00 & 5.92 & 2.33 & -457.77 & 1.04 \\
2 & 23.41 & 274.23 & 6.42 & 2.35 & -603.36 & 1.31 \\
6 & 30.20 & 303.5 & 9.16 & 2.37 & -611.80 & 3.84 \\
$\mathbf{1 0}$ & $\mathbf{3 3 . 7 7}$ & $\mathbf{3 4 1 . 5}$ & $\mathbf{1 1 . 5 3}$ & $\mathbf{2 . 4 1}$ & $\mathbf{6 5 7 . 0 5}$ & $\mathbf{5 . 1 1}$ \\
14 & 31.86 & 305.50 & 9.73 & 2.36 & -549.59 & 4.93 \\
18 & 31.66 & 268.16 & 8.49 & 2.33 & -562.36 & 4.85 \\
20 & 31.87 & 273.00 & 8.70 & 2.34 & -558.75 & 4.62 \\
\hline
\end{tabular}

Best opto-electrical properties are presented in bold

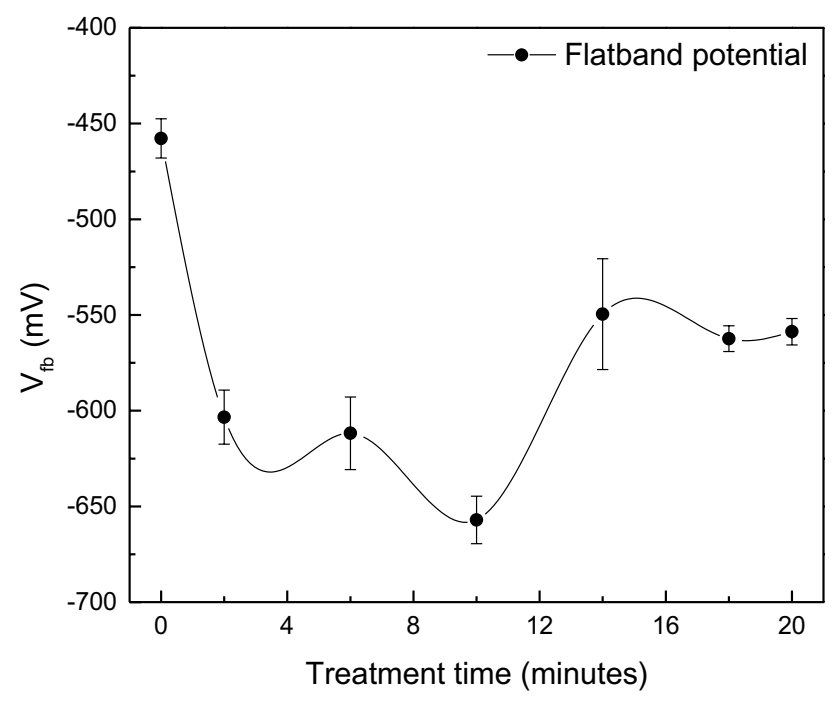

Fig. 7 Flat band potential $\left(V_{f b}\right)$ variation of the $\mathrm{CdCl}_{2}$-treated $\mathrm{CdS}$ thin films

variation, which is caused by the $\mathrm{CdCl}_{2}$ treatment, can be interpreted in terms of variation of carrier concentration (Table 3 ) in the material or due to the presence of intermediate energy states. This suggests, as a result of the $\mathrm{CdCl}_{2}$ treatment, the concentration of donor atoms $\left(N_{D}\right)$ increases due to the recrystallization process which in turn improves the $\left(N_{D}-N_{A}\right)$, where $N_{A}$ is the concentration of acceptors. Additionally, higher $V_{f b}$ produces greater electric field strength in the space charge region, improving the $V_{O C}$ value, hence the photoactivity of the film. Additionally, the tunability of the relative energy band position of the material leads to the improvement of the electrical transport properties of the film, since the formation energy of $\mathrm{V}_{\mathrm{Cd}}{ }^{2+}$ causes band edge position to shift upwards.

\section{Conclusions}

$\mathrm{CdCl}_{2}$ treatment has significantly improved the electrical properties of $\mathrm{CdCl}_{2}$-treated films compared to untreated conventional CdS films. The enhancement of $V_{O C}$ in the
$\mathrm{CdCl}_{2}$-treated films can be concluded as a result of electrical passivation by $\mathrm{CdCl}_{2}$ and electrons states in the grain boundaries. The superior $I_{S C}$ value seen for $\mathrm{CdCl}_{2}$-treated films can be resulted from the improvement in the grain growth process due to diffusion of $\mathrm{Cl}^{-}$in to the $\mathrm{CdS}$ grains. The $E_{g}$ value was found to vary from 2.33 to $2.41 \mathrm{eV}$ along with the $\mathrm{CdCl}_{2}$ treatment time with the highest $E_{g}$ value yielding at a dipping time of $10 \mathrm{~min}$ (S-10).

Furthermore, the occurrence of different relative energy band edge positions can also be a reason for the reported better electrical properties of $\mathrm{CdCl}_{2}$-treated CBD-CdS films in comparison to untreated CBD-CdS. Films dipped for $10 \mathrm{~min}$ in $\mathrm{CdCl}_{2}$ solution appeared to have the highest flat band potential and $V_{O C}$.

Therefore, it can be concluded that the tunability of the relative band edge position, higher effective surface area due to higher roughness, recrystallization, and grain boundary passivation due to $\mathrm{CdCl}_{2}$ treatment has enhanced the electrical properties of the grown thin films. Best electrical and optical properties can be achieved with the treatment time of 10 min in $\mathrm{CdCl}_{2}$ solution.

Acknowledgements This work is financially supported by the Solar Edu-Training project of the Ministry of Science, Technology, and Research, Sri Lanka. Part of the research was performed at the Sensor Lab, Department of Information Engineering, Università Degli Studi Di Brescia, Brescia, Italy.

\section{References}

1. H. Moualkia, S. Hariech, M.S. Aida, Thin Solid Films 518, 12591262 (2009). https://doi.org/10.1016/j.tsf.2009.04.067

2. L. Wan, Z. Bai, Z. Hou, D. Wang, H. Sun, L. Xiong, Thin Solid Films 518, 6858-6865 (2010). https://doi.org/10.1016/j. tsf.2010.07.011

3. C.S. Ferekides, D. Marinskiy, V. Viswanathan, B. Tetali, V. Palekis, P. Selvaraj, D.L. Morel, Thin Solid Films 361-362, 520-526 (2000). https://doi.org/10.1016/S0040-6090(99)00824-X

4. G. Sasikala, R. Dhnasekaran, C. Subramanian, Thin Solid Films 302, 71-76 (1997). https://doi.org/10.1016/S0040-6090(96)09582 $-\mathrm{X}$ 
5. A. Gupta, V. Parikh, A.D. Compaan, Sol. Energy Mater. Sol. Cells 90, 2263-2271 (2006). https://doi.org/10.1016/j.solma t.2006.02.029

6. H.C. Chou, A.R. Ohatgi, J. Electron. Mater. 23, 31 (1994). https ://doi.org/10.1007/BF02651264

7. S.A. Al Kuhaimi, Vacuum 51(3), 349-355 (1998). https://doi. org/10.1016/S0042-207X(98)00112-2

8. O. Savadogo, Chemically and electrochemically deposited thin films for solar energy materials. Sol. Energy Mater. Sol. Cells 52, 361-368 (1998). https://doi.org/10.1016/S0927-0248(97)00247 $-\mathrm{X}$

9. E.X. Mathew, Sol. Energy Mater. Sol. Cells 76, 313-325 (2003). https://doi.org/10.1016/S0927-0248(01)00090-3

10. W.G.C. Kumarage, R.P. Wijesundera, V.A. Seneviratne, C.P. Jayalath, B.S. Dassanayake, J. Phys. D. Appl. Phys. 49, 95109 (2016). https://doi.org/10.1088/0022-3727/49/9/095109

11. W.G.C. Kumarage, L.B.D.R.P. Wijesundara, V.A. Seneviratne, C.P. Jayalath, B.S. Dassanayake, Procedia Eng. 139, 64-68 (2016). https://doi.org/10.1016/j.proeng.2015.09.215

12. W.G.C. Kumarage, R.P. Wijesundera, V.A. Seneviratne, C.P. Jayalath, T. Varga, M.I. Nandasiri, B.S. Dassanayake, Mater. Chem. Phys. 200, 1-8 (2017). https://doi.org/10.1016/j.matchemphy s.2017.07.052

13. W.G.C. Kumarage, L.B.D.R.P. Wijesundara, V.A. Seneviratne, C.P. Jayalath, B.S. Dassanayake, Semicond. Sci. Technol. 32, 045014 (2017). https://doi.org/10.1088/1361-6641/aa5ee3

14. F. Liu, Y. Lai, J. Liu, B. Wang, S. Kuang, Z. Zhang, J. Li, Y. Liu, J. Alloy. Compd. 493, 305-308 (2010). https://doi.org/10.1016/j. jallcom.2009.12.088

15. M. Tsuji, T. Aramoto, H. Ohyama, T. Hibino, K. Omura, Jpn. J. Appl. Phys. 39, 3902-3906 (2000). https://doi.org/10.1143/ JJAP. 39.3902

16. I.M. Dharmadasa, Coatings 4, 282-307 (2014). https://doi. org/10.3390/coatings 4020282

17. J. Salinger, J. Acta Polytechnica 46, 25-27 (2006)

18. M.J. Kim, J.J. Lee, S.H. Lee, S.H. Sohn, Solar Energy Mater. Solar Cells 109, 209-214 (2013). https://doi.org/10.1016/j.solma t.2012.11.012

19. D.B. Laks, C.G. Van de Walle, G.F. Neumark, S.T. Pantelides, Phys. Rev. Lett. 66, 648-651 (1991)

20. M.A. Islam, M.S. Hossain, M.M. Aliyu, M.R. Karim, T. Razykov, K. Sopian, N. Amin, Thin Solid Films 546, 367-374 (2013). https ://doi.org/10.1016/j.tsf.2013.04.067

21. J. Lee, Curr. Appl. Phys. 11(1), 103-108 (2011). https://doi. org/10.1016/j.cap.2010.11.099

22. A. Rios-Flores, J.L. Peña, V. Castro-Peña, O. Ares, R. CastroRodríguez, A. Bosio, Sol. Energy 84(6), 1020-1026 (2010). https ://doi.org/10.1016/j.solener.2010.03.010

23. W.G.C. Kumarage, R.P. Wijesundera, V.A. Seneviratne, C.P. Jayalath, T. Varga, B.S. Dassanayake, Appl. Phys. A 124, 494 (2018). https://doi.org/10.1007/s00339-018-1910-0
24. K.K.M.B.B. Adikaram, W.G.C. Kumarage, T. Varga, B.S. Dassanayake, J. Electron. Mater. 48(7), 4424-4431 (2019). https:// doi.org/10.1007/s11664-019-07215-5

25. W.G.C. Kumarage, R.P. Wijesundera, V.A. Seneviratne, C.P. Jayalath, N. Kaur, E. Comini, B.S. Dassanayake, J. Photochem. Photobiol. A 367, 171-177 (2018). https://doi.org/10.1016/j.jphot ochem.2018.08.029

26. A. Oliva-Avilés, R. Patiño, A. Oliva, Appl. Surf. Sci. 256, 60906095 (2010). https://doi.org/10.1016/j.apsusc.2010.03.125

27. A. Mukherjee, P. Ghosh, A.A. Aboud, P. Mitra, Mater. Chem. Phys. 184, 101-109 (2016). https://doi.org/10.1016/j.matchemphy s.2016.09.030

28. A.I. Oliva, O.S. Canto, R.C. Rodrigues, P. Quintana, Thin Solid Films 391(1), 28-35 (2001). https://doi.org/10.1016/S0040 $-6090(01) 00830-6$

29. A. Kariper, E. Güneri, F. Gödethe, C. Gümüs, T. Özpozan, Mater. Chem. Phys. 129, 183-188 (2011). https://doi.org/10.1016/j.match emphys.2011.03.070

30. S.A. Ringel, A.W. Smith, M.H. MacDougal, A. Rohatgi, J. Appl. Phys. 70(2), 881 (1991). https://doi.org/10.1063/1.349652

31. A. Luque, S. Hegedus, Handbook of photovoltaic science and engineering (John Wiley \& Sons, Chichester, 2011)

32. S. Du, Y. Li, Adv. Mater. Sci. Eng. 2015, 8 (2015). https://doi. org/10.1155/2015/969580

33. V. Bilgin, S. Kose, F. Atay, I. Akyuz, J. Mater. Sci. 40, 1909-1915 (2005). https://doi.org/10.1007/s10853-005-1210-X

34. P.K.K. Kumarasinghe, A. Dissanayake, B.M.K. Pemasiri, B.S. Dassanayake, Mat. Sci. Semicon. Proc. 58, 51-60 (2017). https:// doi.org/10.1016/j.mssp.2016.11.028

35. P.K.K. Kumarasinghe, A. Dissanayake, B.M.K. Pemasiri, B.S. Dassanayake, Mater. Res. Bull. 96, 188-195 (2017). https://doi. org/10.1016/j.materresbull.2017.04.026

36. H.R. Moutinho, R.G. Dhere, M.M. Al-Jassim, D.H. Levi, L.L. Kazmerski, J. Vac. Sci. Technol. A17, 1793 (1999). https://doi. org/10.1116/1.581892

37. A. Nawaz, Z. Rabeel, N.A. Shah, World Appl. Sci. J. 31(8), 1522 1530 (2014). https://doi.org/10.5829/idosi.wasj.2014.31.08.621

38. P.K.K. Kumarasinghe, A. Dissanayake, B.M.K. Pemasiri, B.S. Dassanayake, J. Mater. Sci.: Mater. Electron. 28, 276-283 (2017). https://doi.org/10.1007/s10854-016-5521-2

39. M. Akif, S. Aliyev, M. El-Rouby, Int. J. Thin Film Sci. Technol. 2, 195-2005 (2013). https://doi.org/10.12785/ijtfst/020305

40. W.G.C. Kumarage, R.P. Wijesundera, N. Kaur, D. Zappa, V.A. Seneviratne, C.P. Jayalath, B.S. Dassanayake, Int. J. Electroact. Mater. 7, 1-6 (2019)

Publisher's Note Springer Nature remains neutral with regard to jurisdictional claims in published maps and institutional affiliations. 